\title{
A practical approach to adult-onset white matter diseases, with illustrative cases
}

\author{
Tasneem F. Hasan ${ }^{1}$, Philip W. Tipton ${ }^{2}$, Kenneth A. Vatz ${ }^{6}$, Suzanne M. Brown ${ }^{3}$, Neeharika Thottempu- \\ $\mathrm{di}^{7}$, Prasuna Kamireddi ${ }^{8}$, Paldeep S. Atwal ${ }^{9}$, Zbigniew K. Wszolek ${ }^{2}$, William D. Freeman ${ }^{2,4,5}$ \\ ${ }^{1}$ Department of Neurology, Ochsner Louisiana State University Health Sciences Center, Shreveport, Louisiana, United States \\ ${ }^{2}$ Department of Neurology, Mayo Clinic, Jacksonville, Florida, United States \\ ${ }^{3}$ Department of Nursing, Mayo Clinic, Jacksonville, Florida, United States \\ ${ }^{4}$ Department of Critical Care Medicine, Mayo Clinic, Jacksonville, Florida, United States \\ ${ }^{5}$ Department of Neurosurgery, Mayo Clinic, Jacksonville, Florida, United States \\ ${ }^{6}$ Department of Neurology, Community Health, Chicago, Illinois, United States \\ ${ }^{7}$ Department of Neurology, University of Texas Medical Branch, Galveston, Texas, United States \\ ${ }^{8}$ Department of Neurology, West Virginia University School of Medicine, Morgantown, West Virginia, United States \\ ${ }^{9}$ Department of Medical Genomics, Atwal Clinic, Jacksonville, Florida, United States
}

\section{ABSTRACT}

Aim. To evaluate five illustrative cases and perform a literature review to identify and describe a working approach to adult-onset white matter diseases (WMD).

State of the art. Inherited WMD are a group of disorders often seen in childhood. In adulthood, progressive WMDs are rare, apart from the common nonspecific causes of hypertension and other cerebrovascular diseases. The pattern of WMDs on neuroimaging can be an important clue to the final diagnosis. Due to the adoption of a combined clinical-imaging-laboratory approach, WMD is becoming better recognised, in addition to the rapidly evolving field of genomics in this area.

Clinical implications. While paediatric WMDs have a well-defined and literature-based clinical-laboratory approach to diagnosis, adult-onset WMDs remain an important, pathologically diverse, radiographic phenotype, with different and distinct neuropathologies among the various subtypes of WMD. Adult-onset WMDs comprise a wide collection of both acquired and inherited aetiologies. While severe acute respiratory syndrome coronavirus 2 (SARS-CoV-2) neurological complications are emerging, we are as yet unaware of it causing WMD outside of post-anoxic changes. It is important to recognise WMD as a potentially undefined acquired or genetic syndrome, even when extensive full genome testing reveals variants of unknown significance.

Future directions. We propose a combined clinical-imaging-laboratory approach to WMD and continued exploration of acquired and genetic factors. Adult-onset WMD, even given this approach, can be challenging because hypertension is often comorbid. Therefore, we propose that undiagnosed patients with WMD be entered into multicentre National Organisation for Rare Diseases registries to help researchers worldwide make new discoveries that will hopefully translate into future cures.

Key words: adult-onset, genetic analysis, magnetic resonance imaging, white matter disease, white matter hyperintensities, COVID-19

(Neurol Neurochir Pol 2020; 54 (4): 312-322)

Address for correspondence: William D. Freeman, Department of Neurology, Mayo Clinic, 4500 San Pablo Rd, Jacksonville, FL 32224, USA,

e-mail: freeman.william1@mayo.edu 


\section{Introduction}

White matter diseases (WMD) are a group of brain disorders characterised by either abnormal myelin development (hypomyelination) or a loss of acquired myelin (demyelination). While WMD can be of metabolic origin, the involvement of gene coding for proteins (genetic origin) has been strongly implicated [1].

Furthermore, the widespread use of magnetic resonance imaging (MRI) of the brain has increased the recognition of adult-onset WMD, and the recognition of WMD has similarly paralleled that of multiple sclerosis [2]. Classic inherited WMD must be distinguished from WMD due to acquired causes, such as inflammatory or toxic processes, autoimmune diseases, infections, neoplasms, and WMD, seen in 50-98\% of elderly patients, presumably due to small vessel disease [3]. While there are increasing reports of severe acute respiratory syndrome coronavirus 2 (SARS-CoV-2) causing neurological complications, we are as yet unaware of it causing WMD [4-6]. Furthermore, Köhler et al. [7] and Lynch et al. [8] have recently published comprehensive reviews on the diagnosis, categorisation, and in some cases, treatment of WMD.

We here present five challenging illustrative cases that demonstrate the complexity and difficulty of investigating adult-onset WMDs, especially those of unknown aetiology, and we set out a structured approach to diagnosis.

\section{Case 1: cerebral autosomal dominant arteriopathy with subcortical infarcts and leukoencephalopathy}

A 46-year-old man presented to our institution for a second opinion on a pituitary tumour. His medical history was notable for headaches and cognitive decline, including slowed processing speed. The patient was told he might have multiple sclerosis in addition to the pituitary tumour and was unclear about his underlying condition. His neurological examination showed no evidence of visual impairment, despite the pituitary tumour. His family history was notable for the death of his father and brother from possible stroke. MRI of the brain showed distinct anterior temporal pole WMD, highly suggestive of cerebral autosomal dominant arteriopathy with subcortical infarcts and leukoencephalopathy (CADASIL) (Fig. 1) [9].

The neuro-ophthalmology and neurosurgery consultants felt that his pituitary tumour was incidental, and recommended the investigation of other causes of his headache and cognitive impairment. The patient agreed to undergo genetic evaluation and counselling. A commercial single gene test for a NOTCH3 gene mutation was positive, thus confirming a diagnosis of CADASIL [10]. The patient underwent risk factor modification and education for his mild systemic hypertension and obstructive sleep apnoea, and his family was advised to seek outpatient genetic counselling for their daughter.

\section{Case 2: unknown WMD}

A 75-year-old right-handed white woman with a history of hypertension, hyperlipidemia, and osteoporosis was followed over 11-years in our neurology clinic for intermittent progression of numbness and tingling of her left upper and lower extremities, as well as cognitive decline with subsequent inability to perform activities of daily living. She also reported dizziness (dysequilibrium), multiple falls, and left visual field difficulty, but no hearing loss. The patient had an unremarkable birth history, and no history of neurological milestone delays or dysmorphic features. She denied a history of tobacco, alcohol, or recreational drug use. Her home medications included simvastatin $20 \mathrm{mg}$ daily, aspirin $325 \mathrm{mg}$ daily, and multivitamins. She had no known family history of WMD. On neurological examination, she was alert and oriented, with intact speech and cranial nerves. Neuropsychological testing revealed cognitive difficulties characterised by impairment in executive function, visuospatial skills, and visuoconstruction. Auditory attention, verbal learning and memory, and language remained essentially intact.

On confrontational field testing, a progression from left quadrantanopia to left homonymous hemianopia was noted and confirmed on formal perimetry. Serial funduscopic examinations

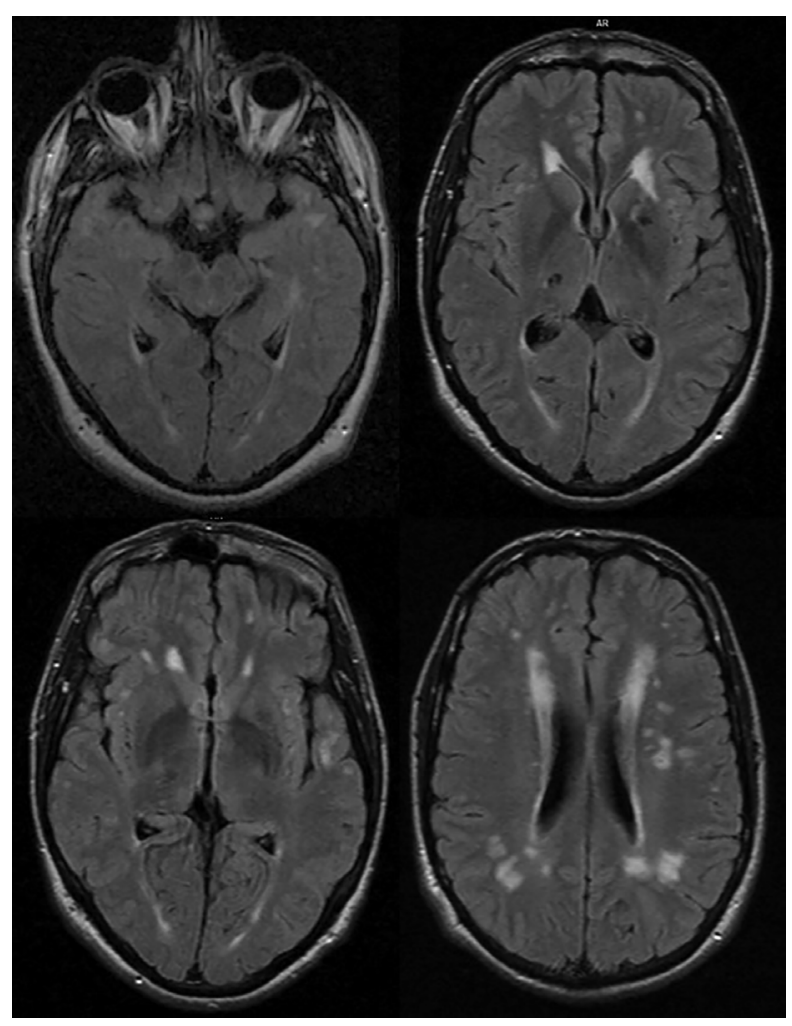

Figure 1. Case 1: T2 FLAIR MRI of the brain. Imaging shows hyperintensities in the anterior temporal pole concerning for cerebral autosomal dominant arteriopathy with subcortical infarcts and leukoencephalopathy 

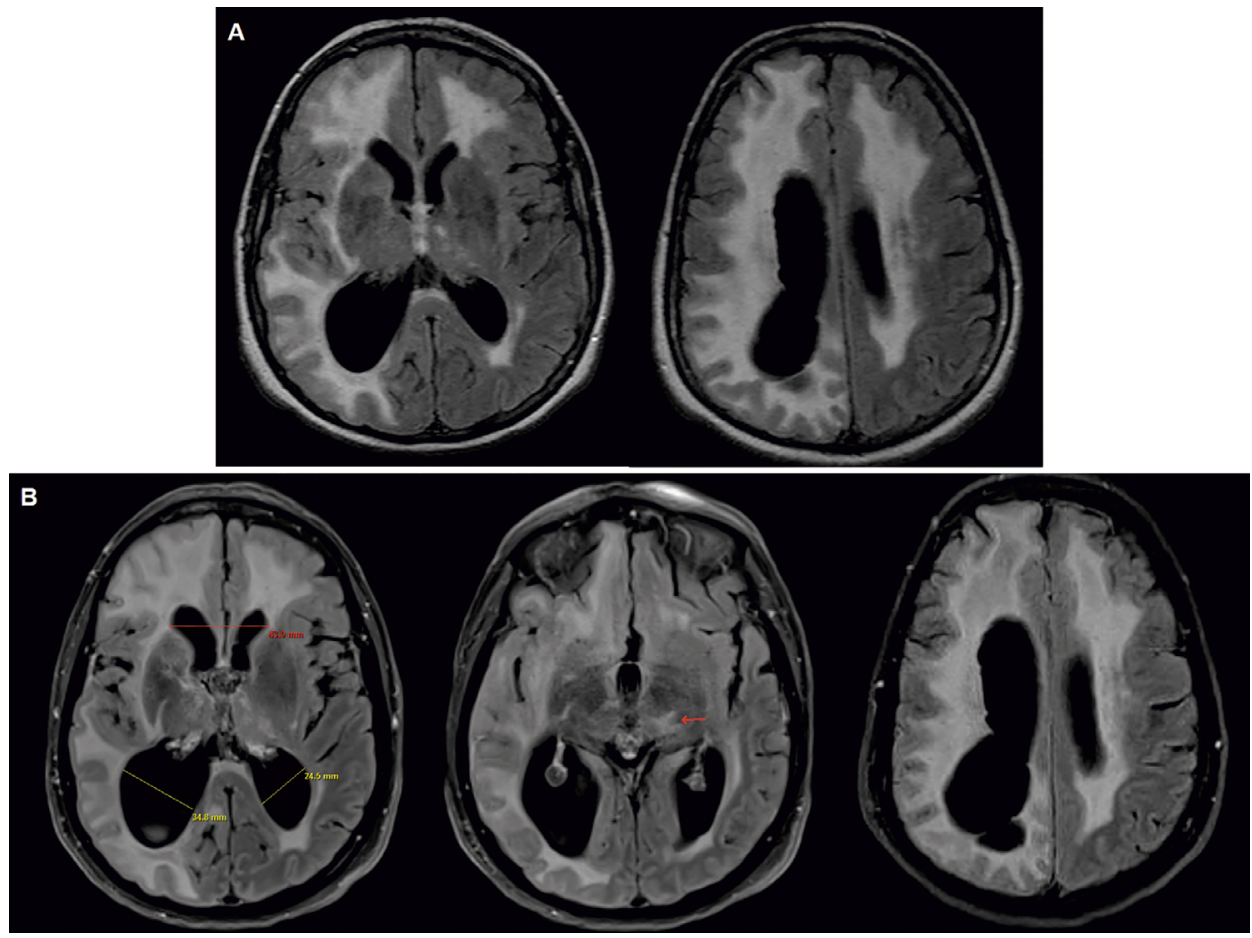

Figure 2. Case 2: T2 FLAIR MRI of the brain. A. Imaging from 2006 demonstrates large areas of confluent hyperintensities involving the white matter of the bilateral cerebral hemispheres, right > left. Associated volume loss is greater on the right, with moderate enlargement of the right lateral ventricle, particularly posteriorly. B. Imaging from 2014 demonstrates stable volume loss (bifrontal ventricular horns [Evan's index] $43.0 \mathrm{~mm}$; right posterior lateral ventricle $34.8 \mathrm{~mm}$; left posterior lateral ventricle $24.5 \mathrm{~mm}$ ) and confluent cerebral white matter disease, right > left, with thalamic hyperintensities (red arrow)

were unremarkable. She gradually developed postural instability, left spastic hemiparesis (Medical Research Council grade 4/5), and brisk left-sided reflexes (3+) with a left Babinski sign. Myoclonus and Hoffman and Tromner signs were absent. There was diminished pin-prick sensation, vibration, and proprioception in the left upper and lower extremities, with a positive Romberg sign and the presence of pseudoathetoid movements. Fine motor movements were diminished, and left-sided dysmetria and ataxic gait were noted. Orthostatic blood pressure testing was negative and autonomic function appeared to be normal.

In 2006, T2 fluid-attenuated inversion recovery (FLAIR) MRI of the brain revealed diffuse large confluent white matter hyperintensities with abnormal signal intensity in the bilateral thalami with right hemisphere brain volume loss and moderate enlargement of the right lateral ventricle (ex vacuo), consistent with WMD (Fig. 2A). Despite a progression in symptoms, imaging in 2014 demonstrated stable volume loss (bifrontal ventricular horns [Evan's index] $43.0 \mathrm{~mm}$; right posterior lateral ventricle $34.8 \mathrm{~mm}$; left posterior lateral ventricle $24.5 \mathrm{~mm}$ ) and confluent cerebral WMD, right > left, with thalamic hyperintensities (red arrow) (Fig. 2B)[11]. Magnetic resonance spectroscopy demonstrated a decrease in all major metabolites (e.g. $\mathrm{N}$-acetyl aspartate, choline, and creatine) consistent with nonspecific neuronal loss. A fluorodeoxyglucose PET scan of the brain showed globally decreased metabolism in the right hemisphere. Cervical, thoracic, and lumbar MRI were unremarkable. Comprehensive testing, including a battery of tests for inherited WMD, was negative (Tab. 1). Based on the available clinical, laboratory, genetic, and imaging data, the patient was diagnosed with WMD of unknown aetiology.

While this case is unusual, it demonstrates that even with advanced imaging and the most up-to-date genetic and laboratory repertoires, cases of WMD of unknown aetiology still exist that may be the result of sporadic genetic mutation. In these cases, it is important to follow the patient's neurological condition over time and continue to search for important clues in the family history or other factors. Similar to the management of other neurodegenerative diseases, it is necessary to recognise the degree of neurological impairment and to prescribe rehabilitative services, such as physical and occupational therapy to prevent falls.

\section{Case 3: 'Chasing the dragon' leukoencephalopathy}

A 42-year-old man with a history of opiate addiction presented to the emergency department with coma and hypoxemic respiratory arrest. He required transient intubation and mechanical ventilation, and was given naloxone intravenously. Upon wakening, he was able to follow commands and was 
Table 1. Case 2 - Unknown WMD: negative comprehensive testing results

\begin{tabular}{|c|c|}
\hline Type of Testing & Specific Tests \\
\hline Routine labs & $\begin{array}{l}\text { - Comprehensive metabolic panel } \\
\text { - Vitamin B12 } \\
\text { - Folate } \\
\text { - Methylmalonic acid } \\
\text { - Homocysteine } \\
\text { - Thyroid profile }\end{array}$ \\
\hline Autoimmune & $\begin{array}{l}\text { - Cytoplasmic antineutrophil cytoplasmic antibodies } \\
\text { - Perinuclear antineutrophil cytoplasmic antibodies } \\
\text { - Anti-double-stranded DNA } \\
\text { - Rheumatoid factor } \\
\text { - Antiphospholipid antibody } \\
\text { - Thyroid peroxidase antibody }\end{array}$ \\
\hline Infection & $\begin{array}{l}\text { - Human immunodeficiency virus } \\
\text { - Herpes simplex virus } \\
\text { - Human T-cell lymphotropic virus } \\
\text { - Whipple disease } \\
\text { - Syphilis } \\
\text { - St. Louis encephalitis } \\
\text { - Varicella-zoster virus } \\
\text { - Epstein-barr virus } \\
\text { - Cytomegalovirus } \\
\text {-West Nile virus } \\
\text { - John Cunningham virus } \\
\text { - Lyme disease } \\
\text { - Brucella }\end{array}$ \\
\hline Mitochondrial/genetic & $\begin{array}{l}\text { - Normal-to-low venous lactate levels excluded mitochondrial disorder } \\
\text { - Comprehensive leukodystrophy/leukoencephalopathy and mitochondrial DNA genetic testing } † \\
\text {-Whole-exome sequencing revealed a variant of undetermined significance in gene TRPA1 }\end{array}$ \\
\hline Inherited WMD‡ & $\begin{array}{l}\text { - Metachromatic leukodystrophy (arylsulfatase A, urine sulfatides) } \\
\text { - Tay-Sachs disease (hexosaminidase A) } \\
\text { - Peroxisomal disorders (long-chain fatty acids) } \\
\text { - Adrenoleukodystrophy (very long-chain fatty acids) } \\
\text { - CADASIL (NOTCH3) } \\
\text { - Childhood ataxia with central hypomyelination or vanishing WMD (EIF2B1-5) } \\
\text { - Hereditary diffuse leukoencephalopathy with axonal spheroids (CSF1R) } \\
\text { - Krabbe disease (galactosylceramidase) } \\
\text { - Organic acidemia (urine organic acid analysis) }\end{array}$ \\
\hline Additional testing & $\begin{array}{l}\text {-EMG/NCV: mild neuropathy } \\
\text { - EEG: delta slowing with occasional sharp activity in the right temporal and parietal regions; no evidence } \\
\text { of electrographic seizures } \\
\text { - Lumbar puncture: negative for inflammatory causes; negative for oligoclonal bands and immunoglobulin } \\
\text { G index; negative paraneoplastic panel } \\
\text {-Visual- and brainstem auditory-evoked response tests were normal }\end{array}$ \\
\hline
\end{tabular}

CADASIL — cerebral autosomal dominant arteriopathy with subcortical infarcts and leukoencephalopathy; CSF1R - colony stimulating factor 1 receptor; DNA — deoxyribonucleic acid; EEG — electroencephalogram; EIF2B1-5 - eukaryotic translation initiation factor 2b; EMG - electromyography; NCV - nerve conduction velocity; NOTCH3 - neurogenic locus notch homolog protein 3; TRPA 1 - transient receptor potential ankyrin 1 ; WMD - white matter disease

tGenes assessed by this test: ABAT, ABCD1, ACOX1, ADAR, ADK, AIMP1, ALDH3A2, APOA1BP, APOPT1, ARCN1, ARSA, ASPA, ASXL2, AUH, B3GALNT2, BCL11B, C200RFZ, C8ORF38, CCDC88A, CLCN2, CLN6, COL4A1, COX15, CSF1R, CTNS, CYP27A1, DARS, DARS2, EARS2, EIF2B1, EIF2B2, EIF2B3, EIF2B4, EIF2B5, FA2H, FAM126A, FBXLA, FKRP, GALC, GFAP, GJC2, GPR56, HEPACAM, HSPD1, HTRA1, ITPA, KCNT1, L2HGDH, LMNB1, MARS2, MLC1, MLYCD, MPV17, MRPS22, MTFMT, MTTP, NDUFA1, NDUFA10, NDUFA11, NDUFA12, NDUFA2, NDUFA9, NDUFAF1, NDUFAF2, NDUFAF3, NDUFAF4, NDUFB3, NDUFS1, NDUFS2, NDUFS3, NDUFS4, NDUFS6, NDUFS7, NSUFS8, NDUFV1, NDUFV2, NOTCH3, NUBPL, OMG, PAH, PC, PHGDH, PSAP, PTEN, PUS3, RNASEH2A, RNASEH2B, RNASEH2C, SAMHD1, SCP2, SDHA, SDHAF1, SDHB, SLC1A2, SLC1A4, SLC16A2, SLC25A12, SLCBA9, SNORD118, SNRPB, SON, SOX10, STXBP1, TACO1, TARS2, TBCD, TMTC3, TREM2, TREX1, TUBB4, TUFM, TYMP, TYROBP, VARS2

¥Sjögren-Larsson syndrome, adult polyglucosan body disease, leukoencephalopathy with brainstem and spinal cord involvement and lactate elevation, neuronal ceroid-lipofuscinosis, megalencephalic leukoencephalopathy with subcortical cysts, merosin-deficient congenital muscular dystrophy, molybdenum cofactor deficiency, sulfide oxidase deficiency, $\mathrm{L}-2$ hydroxyglutaric aciduria, propionic acidemia, adult-onset Canavan disease, and urea cycle deficits were low on the differential 
subsequently extubated and discharged home. However, after returning home, his wife reported that he became somnolent with intermittent apnoeic episodes overnight. His family brought him back to the ED and he was again unresponsive. He was reintubated and admitted to the intensive care unit and extubated a few days later. The patient, however, remained cognitively impaired, and over the next 30 days developed a progressive decline in neurological function, including mild parkinsonism, poor short-term memory and concentration, and behavioural changes including disinhibition and hypersexuality. Delayed MRI of the brain showed diffuse white matter abnormalities (Supplemental Fig. 1A). Laboratory testing for congenital leukoencephalopathies was negative, including arylsulfatase A and galactosylceramidase, which excluded adult-onset metachromatic leukodystrophy and Krabbe disease, respectively. While the patient's clinical condition and MRI findings gradually improved over the next six months (Supplemental Fig. 1B), he never returned to his prior normal neurological baseline.

The patient's family revealed that he had been inhaling heroin vapour, a practice known as "chasing the dragon" which can cause acute toxic (or spongiform) leukoencephalopathy due to leukotoxins [12-14]. Given the opioid epidemic in the United States, this condition could become increasingly prevalent. Coenzyme Q10 has been proposed as a potential therapeutic agent, along with ongoing anti-opioid efforts to reduce disease incidence [15].

\section{Case 4: WMD with axonal spheroids and pigmented glia}

A 37-year-old woman presented with an 11-month history of progressive gait dysfunction that had begun with a tendency for her left foot to turn in when walking. This progressed to considerable balance difficulties. At our first evaluation, her neurological examination was notable only for mild ataxia involving the left arm and leg. She had a family history of similar symptoms that appeared to be dominantly inherited paternally. Laboratory testing of metabolic, haematological, autoimmune, rheumatological, infectious, and neoplastic entities were unremarkable, as was her cerebrospinal fluid (CSF) profile. Formal neuropsychological testing showed mild cognitive impairment with deficits in complex attention, processing speed, and fine motor speed. Non-contrast computed tomography (CT) of the head showed bilateral frontoparietal atrophy without calcifications. MRI of the brain showed severe cortical atrophy of the parietal lobes, and to a lesser extent, the frontal lobes, as well as periventricular and subcortical hyperintensities on T2 FLAIR sequence (Fig. 3).

At follow-up 12-months later, she reported difficulty with multi-tasking, spelling, and performing mental calculations. She was also experiencing slurred speech, worsening balance, and difficulty using her left hand, which would move involuntarily. Notwithstanding these difficulties, she remained independent with her activities of daily living. Neurological examination demonstrated dysarthria and left-sided predominant apraxia, ataxia, and spasticity that severely affected her gait. Genetic testing demonstrated a pathologic mutation in the CSF1R gene.

$C S F 1 R$ is a tyrosine kinase receptor and is the causative gene for axonal spheroids and pigmented glia, also known as CSF1R-related leukoencephalopathy. More than 70 mutations have been shown to disrupt the function of CSF1R in the brain microglia, leading to their dysfunction [16]. Brain biopsy was previously the only means of diagnosing this disease; however, genetic testing has now removed the need for such an invasive procedure. Axonal spheroids with pigmented glia is currently considered to be a progressive incurable WMD, though case studies have suggested that haematopoietic stem cell transplantation may be beneficial $[17,18]$. Although the mechanism of this treatment is not entirely understood, it is thought that haematopoietic stem cell transplantation may lead to replenishment of a healthy microglial population.

\section{Case 5: WMD from COVID-19 post-anoxic encephalopathy}

A 70-year-old man developed COVID-19 pneumonia and progressive hypoxaemia requiring intubation, sedation, and mechanical ventilation. He developed adult respiratory
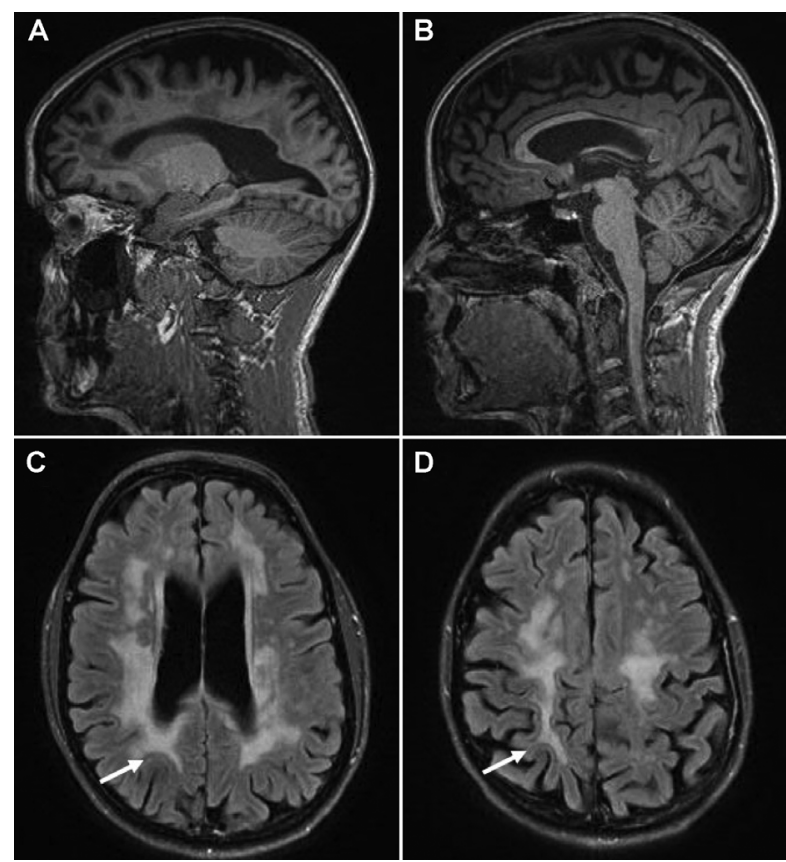

Figure 3. Case 4: MRI of the brain. A. Sagittal T1 MRI shows predominantly parietal and frontal lobe cortical atrophy with ex vacuo ventriculomegaly, and $B$. thinning of the corpus callosum. C. and D. Axial T2 FLAIR MRI shows hyperintensities in the periventricular and subcortical regions, with sparing of the cortical U-fibres (arrows) 


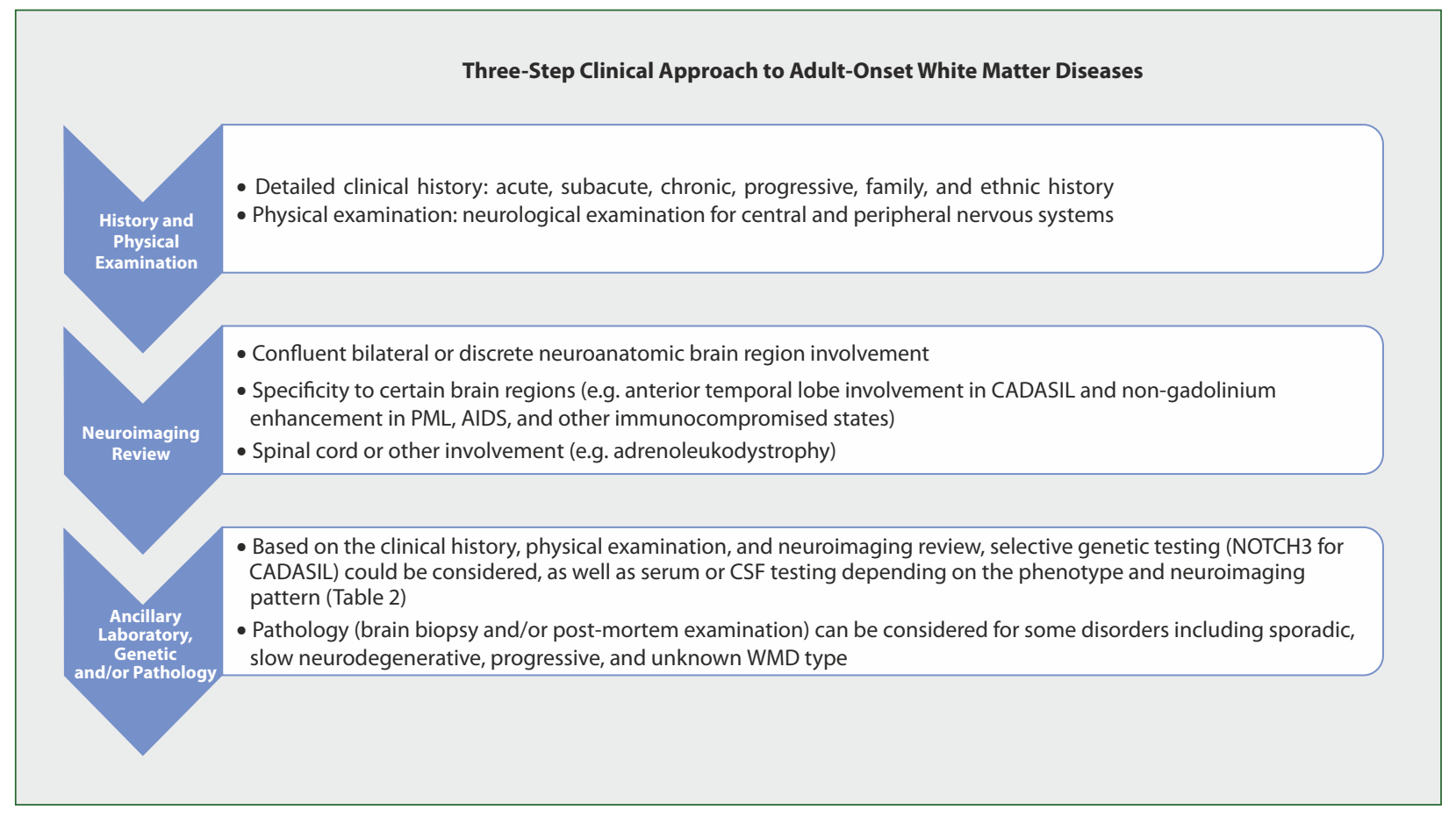

Figure 4. Three-step clinical approach to adult-onset white matter diseases.

AIDS - acquired immunodeficiency syndrome; CADASIL - cerebral autosomal dominant arteriopathy with subcortical infarcts and leukoencephalopathy; CSF - cerebrospinal fluid; NOTCH3 - neurogenic locus notch homolog protein 3; PML - progressive multifocal leukoencephalopathy; WMD - white matter disease

distress syndrome and multiorgan failure including renal failure and critical illness myopathy on electromyography. He eventually received a tracheostomy after his nasopharyngeal COVID-19 test was negative and developed SARS-CoV-2 IgG antibodies. After a month of hospitalisation, he was transported to a chronic care facility for rehabilitation, but suffered unresponsiveness and severe hypoxia (pulse oximeter in the 70 s) despite increasing his fractional inspired oxygen $\left(\mathrm{FiO}^{2}\right)$. Arterial blood gas showed an acute severe acidosis, with $\mathrm{pH}$ of $6.95, \mathrm{PaCO}^{2}$ of 135 , and $\mathrm{PaO}^{2}$ of 95 on $100 \% \mathrm{FiO}^{2}$. He later developed left facial focal twitching; electroencephalogram confirmed generalised periodic discharges. Non-contrast CT head imaging showed hypodense frontal white matter with a subtle loss in grey-white matter differentiation (Supplemental Fig. 2A). T2 FLAIR MRI of the brain showed severe bilateral hyperintensities in the subcortical and cortical white matter, particularly in the left occipital cortical regions, consistent with global hypoxic-brain injury (Supplemental Fig. 2B). Susceptibility weighted imaging (SWI) showed diffuse microhaemorrhages (Supplemental Fig. 2C). Given his overall poor prognosis, palliative care was discussed with his family.

This case demonstrates a straightforward post-hypoxic cause of white matter changes similar to cardiac arrest, which is a direct neuronal injury to the cortex, white matter neurons, and astrocytes. However, the emergence of COVID-19 cases of demyelinating disease have also been reported similar to multiple sclerosis with gadolinium enhancement [19]. This patient's MRI of the brain and cervical and thoracic spine with and without contrast failed to reveal any contrast enhancement. Multiple microhaemorrhages seen on SWI have also been reported in COVID-19, and may represent an underlying microvasculopathy of the disease. In one of the largest neuroimaging studies on COVID-19, 35\% of patients had non-specific white matter changes noted on CT and/or MRI. Some patients were also noted to have acute cerebrovascular, hypoxic, and post-ictal changes on neuroimaging [20].

Given the global prevalence of COVID-19, and assuming the $35 \%$ baseline WMD changes seen on neuroimaging, these changes may in fact reflect small vessel disease secondary to chronic hypertension. However, clinicians should be aware of other autoimmune/demyelinating variants where the history and imaging are supportive of it.

\section{Discussion}

WMDs comprise an array of clinical, genetic, and pathophysiologically distinct entities, including acquired progressive diseases such as demyelinating disorders and nonspecific cerebrovascular WMD seen with hypertension, diabetes mellitus, and renal dysfunction (Tab. 2). Some cases of WMD may represent an undefined genetic syndrome or variants of unknown significance, which are areas on extensive full genome testing 
Table 2. Adult- and paediatric-onset white matter disease

\begin{tabular}{|c|c|c|c|c|c|}
\hline \multirow[b]{2}{*}{ Disorder } & \multicolumn{4}{|c|}{ Inherited adult-onset WMD } & \multirow[b]{2}{*}{$\begin{array}{l}\text { MRI (T1, T2, FLAIR) increased } \\
\text { signal }\end{array}$} \\
\hline & $\begin{array}{c}\text { Genetic } \\
\text { inheritance }\end{array}$ & $\begin{array}{c}\text { Lab } \\
\text { diagnosis }\end{array}$ & $\begin{array}{c}\text { Gene } \\
\text { mutation }\end{array}$ & Clinical features & \\
\hline MLD† & AR & $\begin{array}{l}\text { ARSA en- } \\
\text { zyme }\end{array}$ & ARSA & $\begin{array}{l}\text { - Behavioural and psychiatric } \\
\text { changes } \\
\text { - Cognitive decline and gait } \\
\text { disturbance } \\
\text { - Peripheral neuropathy }\end{array}$ & $\begin{array}{l}\text { - Diffuse, symmetric WMH (T2, FLAIR) } \\
\text { - Abnormal periventricular myelin (T2, } \\
\text { FLAIR) } \\
\text { - Sparing of subcortical U-fibres } \\
\text { - T1 increased signal }\end{array}$ \\
\hline CADASIL & $A D$ & $\begin{array}{l}\text { Genetic } \\
\text { testing }\end{array}$ & NOTCH3 & $\begin{array}{l}\text { - Atypical migraine; recurrent } \\
\text { ischaemic events } \\
\text { - Cognitive decline }\end{array}$ & $\begin{array}{l}\text { - Nodular to diffuse periventricular } \\
\text { WMH } \\
\text { - Anterior temporal lobe WMH (T2, } \\
\text { FLAIR) and prolonged T1 and T2 } \\
\text { relaxation times }\end{array}$ \\
\hline HDLS & $A D$ & $\begin{array}{l}\text { Molecular } \\
\text { genetic } \\
\text { testing }\end{array}$ & CSF1R & $\begin{array}{l}\text { - Behavioural changes, ataxia, } \\
\text { seizures } \\
\text { - Pyramidal and extrapyramidal } \\
\text { signs }\end{array}$ & $\begin{array}{l}\text { - Bilateral, asymmetric, confluent WMH } \\
\text { (T2, FLAIR) } \\
\text { - Frontal predominance }\end{array}$ \\
\hline Krabbe disease $\neq$ & AR & $\begin{array}{l}\text { GALC en- } \\
\text { zyme }\end{array}$ & GALC & $\begin{array}{l}\text { - Cognitive decline and gait } \\
\text { disturbance } \\
\text { - Peripheral neuropathy } \\
\text { - Vision loss }\end{array}$ & $\begin{array}{l}\text { - Centrum semiovale, periventricular, } \\
\text { and deep subcortical WMH (T2, } \\
\text { FLAIR) }\end{array}$ \\
\hline$X-A L D$ & X-linked & $\begin{array}{l}\text { VLCFA mea- } \\
\text { surement }\end{array}$ & $A B C D 1$ & $\begin{array}{l}\text { - Dementia, ataxia, spastic para- } \\
\text { paresis } \\
\text { - Neurogenic bladder, bowel } \\
\text { dysfunction, sexual dysfunction, } \\
\text { peripheral neuropathy }\end{array}$ & $\begin{array}{l}\text { - Occipital predominance for WMH } \\
\text { (T2, FLAIR) } \\
\text { - Splenium of corpus callosum and } \\
\text { posterior limb of internal capsule } \\
\text { involvement } \\
\text { - Spinal cord atrophy }\end{array}$ \\
\hline VWM & AR & $\begin{array}{l}\text { CSF asialo- } \\
\text { transferrin }\end{array}$ & EIF2B1-5 & $\begin{array}{l}\text { - Ataxia, spastic paraparesis } \\
\text { - Cognitive decline, depression }\end{array}$ & $\begin{array}{l}\text { - Diffuse WMH especially infratentorial } \\
\text { (T2, FLAIR) } \\
\text { - Marked diffuse atrophy of brain with } \\
\text { ex vacuo ventriculomegaly, cerebel- } \\
\text { lum, and corpus callosum }\end{array}$ \\
\hline Tay-Sachs disease & AR & $\begin{array}{l}\beta \text {-HEXA } \\
\text { enzyme }\end{array}$ & HEXA & $\begin{array}{l}\text { - Psychosis, mood disorders } \\
\text { - Cognitive decline }\end{array}$ & - Severe cerebellar atrophy \\
\hline & & & Acquired a & dult-onset WMD & \\
\hline Disorder & $\begin{array}{l}\text { Aetiological } \\
\text { factors }\end{array}$ & $\begin{array}{l}\text { Lab } \\
\text { diagnosis }\end{array}$ & & Clinical features & MRI (T2 FLAIR) findings \\
\hline $\begin{array}{l}\text { Acute toxic leuko- } \\
\text { encephalopathy } \\
\text { from heroin vapour } \\
\text { inhalation 'Chasing } \\
\text { the dragon' }\end{array}$ & $\begin{array}{l}\text { Inhalation of } \\
\text { heroin vapour } \\
\text { and 'leukoto- } \\
\text { xins' }\end{array}$ & $\begin{array}{l}\text { Urine toxico- } \\
\text { logy/ } \\
\text { /microscopy } \\
\text { - spongiform } \\
\text { leukoencep- } \\
\text { halopathy }\end{array}$ & & $\begin{array}{l}\text { - Pseudobulbar speech, ataxia } \\
\text { - Pyramidal tract signs, hyperacti- } \\
\text { ve reflexes } \\
\text { - Stretching spasms, akinetic } \\
\text { mutism, central pyrexia }\end{array}$ & $\begin{array}{l}\text { - Diffuse, symmetric WMH } \\
\text { - Cerebellum, posterior cerebrum, } \\
\text { and posterior limbs of the internal } \\
\text { capsule involvement } \\
\text { - Posterior-anterior supratentorial } \\
\text { white matter gradient }\end{array}$ \\
\hline $\begin{array}{l}\text { Acute toxic leuko- } \\
\text { encephalopathy } \\
\text { from methamphe- } \\
\text { tamine use or khat }\end{array}$ & $\begin{array}{l}\text { Methamphe- } \\
\text { tamine abuse } \\
\text { and recently } \\
\text { khat, a similar } \\
\text { drug }\end{array}$ & $\begin{array}{l}\text { Urine toxico- } \\
\text { logy/ } \\
\text { /microscopy } \\
\text { - spongiform } \\
\text { leukoencep- } \\
\text { halopathy }\end{array}$ & & $\begin{array}{l}\text { - Mental deterioration, seizures, } \\
\text { nystagmus, focal neurological } \\
\text { deficits } \\
\text { - Catatonic state or 'khatatonia' } \\
\text { from khat, an amphetamine-like } \\
\text { substance }\end{array}$ & $\begin{array}{l}\text { - Diffuse, bilateral, symmetrical lesions } \\
\text { in the subcortical white matter and } \\
\text { corpus callosum } \\
\text { - Sparing of the U-fibres and basal } \\
\text { ganglia } \\
\text { - Reversal of findings after discontinu- } \\
\text { ation of drug }\end{array}$ \\
\hline
\end{tabular}


Table 2 cont. Adult- and paediatric-onset white matter disease

\begin{tabular}{|c|c|c|c|c|c|}
\hline $\begin{array}{l}\text { PML from JC Virus } \\
\text { or } \\
\text { HIV/AIDS }\end{array}$ & Acquired & $\begin{array}{l}\text { Lumbar } \\
\text { puncture/ } \\
\text { /brain biopsy }\end{array}$ & & $\begin{array}{l}\text { - Mental deterioration, vision loss, } \\
\text { speech difficulty } \\
\text { - Ataxia, paralysis, seizures }\end{array}$ & $\begin{array}{l}\text { - Multifocal, bilateral, asymmetrical } \\
\text { lesions involving the subcortical and } \\
\text { periventricular white matter } \\
\text { - Supratentorial lesions } \\
\text { - Parieto-occipital predominance } \\
\text { - U-fibres may be involved }\end{array}$ \\
\hline $\begin{array}{l}\text { Hypertension- } \\
\text {-induced RPLS }\end{array}$ & Acquired & $\begin{array}{l}\text { Blood } \\
\text { pressure me- } \\
\text { asurement }\end{array}$ & & $\begin{array}{l}\text { - Altered mental status, headache } \\
\text { - Abnormal visual perception } \\
\text { - Seizures }\end{array}$ & $\begin{array}{l}\text { - Reversible white matter lesions } \\
\text { - Parieto-occipital predominance }\end{array}$ \\
\hline \multicolumn{6}{|c|}{ Paediatric-onset WMD } \\
\hline Disorder & $\begin{array}{l}\text { Genetic inhe- } \\
\text { ritance }\end{array}$ & $\begin{array}{l}\text { Lab } \\
\text { diagnosis }\end{array}$ & $\begin{array}{c}\text { Gene } \\
\text { mutation }\end{array}$ & Clinical features & MRI (T2 FLAIR) findings \\
\hline Alexander Disease & $A D$ & $\begin{array}{l}\text { Molecular } \\
\text { genetic } \\
\text { testing }\end{array}$ & GFAP & $\begin{array}{l}\text { - Dysphagia, dysarthria, dysp- } \\
\text { honia } \\
\text { - Spastic paraplegia, palatal myoc- } \\
\text { lonus, tremor } \\
\text { - Autonomic dysfunction }\end{array}$ & $\begin{array}{l}\text { - Diffuse, symmetric WMH involving } \\
\text { the frontoparietal regions } \\
\text { - Atrophy of the medulla and upper } \\
\text { cervical cord }\end{array}$ \\
\hline Canavan Disease & AR & $\begin{array}{l}\text { Urine } \\
\mathrm{N} \text {-acetyl } \\
\text { aspartic acid } \\
\text { levels }\end{array}$ & ASPA & $\begin{array}{l}\text { - Macrocephaly, lack of head } \\
\text { control } \\
\text { - Hypotonia }\end{array}$ & $\begin{array}{l}\text { - Diffuse, symmetric WMH in the sub- } \\
\text { cortical areas } \\
\text { - Bilateral globus pallidus involvement }\end{array}$ \\
\hline PMD & X-linked & $\begin{array}{l}\text { Genetic } \\
\text { testing }\end{array}$ & PLP1 & $\begin{array}{l}\text { - Ataxia, spasticity, hypotonia } \\
\text { - Cognitive decline }\end{array}$ & $\begin{array}{l}\text { - Diffuse WMH, with cerebellum and } \\
\text { brain stem involvement }\end{array}$ \\
\hline
\end{tabular}

$A B C D 1$ - peroxisomal ABC half-transporters ALDP; AD — autosomal dominant; AIDS - acquired immunodeficiency syndrome; AR - autosomal recessive; ARSA — arylsulfatase A; ASPA — aspartoacylase; CADASIL - cerebral autosomal dominant arteriopathy with subcortical infarcts and leukoencephalopathy; CSF - cerebrospinal fluid; CSF1R - colony stimulating factor 1 receptor; EIF2B1-5 - eukaryotic translation initiation factor 2B; FLAIR - fluid-attenuated inversion recovery; GALC - galactosylceramidase; GFAP — glial fibrillary acidic protein; HDLS - hereditary diffuse leukoencephalopathy with neuroaxonal spheroids; HEXA - hexosaminidase; HIV — human immunodeficiency virus; JC — John Cunningham; MLD - metachromatic leukodystrophy; MRI — magnetic resonance imaging; NOTCH3 - neurogenic locus notch homolog protein 3; PLP1 - proteolipid protein 1; PMD - Pelizaeus-Merzbacher Disease; PML - progressive multifocal leukoencephalopathy; RPLS - reversible posterior leukoencephalopathy syndrome; VLCFA — very long chain fatty acid; VWM — vanishing white matter disease; WMH — white matter hyperintensity; X-ALD — - -linked adrenoleukodystrophy tLate infantile MLD characterised by weakness hypotonia, dysarthria, spasticity, seizures, compromised vision and hearing; Juvenile MLD characterised by decline in school performance, behavioural problems; MRI changes are similar to adult disease

‡Paediatric-onset Krabbe Disease characterised by progressive neurological deterioration, muscle hypertonicity, irritability, and peripheral neuropathy

not known to be associated with certain diseases [1, 13, 21-24]. Variants of unknown significance are challenging since they might or might not represent actual genetic pathogenicity to the patient's condition [25]. In rare or sporadic gene mutations, there may not be an adequate number of global cases to know whether the gene variant of unknown significance in question is or is not related. While MRI and advanced genetic testing aid in the diagnosis of WMD, atypical cases of unknown aetiology present a continuing challenge.

We recommend a systematic approach to these patients. We have drawn up several steps to increase the likelihood of reaching an accurate diagnosis (Fig. 4).

\section{Step 1: Detailed history and neurological examination}

A methodical approach to WMD is critical to establish an aetiological diagnosis. We suggest a process consisting of a detailed history and a comprehensive neurological examination with neuropsychological testing.

The detailed history should include a family history or a pedigree to better understand the patterns of inheritance (e.g. autosomal dominant, autosomal recessive, X-linked, or sporadic) in efforts to obtain cost-effective genetic screening. Family history is thus helpful in diagnosing inherited WMDs. Nonetheless, patients often provide an incomplete family history, limiting the sensitivity of potential selected genetic testing. Also, family history is not just pedigree-based, but requires detailed investigation into the ethnic background. For example, asking about a particular ethnic history of Ashkenazi Jewish (neuronal ceroid lipofuscinosis), Asian-Indian, or Turkish (Behçet syndrome) descent may help to differentiate specific forms of leukoencephalopathy [1]. The demographics of Case 2 revealed no such ethnic association.

In addition, it is important to obtain where possible a pregnancy and perinatal history, as white matter abnormalities and hypomyelination can result from exposure to alcohol, methamphetamine, and cocaine. [26-29]

Neurological signs and symptoms, including peripheral neuropathy, cerebellar ataxia, spastic weakness, and dystonic dyskinetic movements, which may be found in specific forms of WMD [1], should be explored because they may provide additional information to the diagnosis. Progressive unilateral 
symptoms in the presence of drug-resistant focal epilepsy and cognitive decline raises the possibility of Rasmussen encephalitis. The absence of one or a group of symptoms does not exclude WMD [1]. Case 2 presented with various symptoms, but tests for specific forms of WMD were negative.

The COVID-19 pandemic has emerged with increasing reports of devastating diencephalic encephalitis. While WMD might be occurring from this disease, we are unaware of any formal study. COVID-19 neurological manifestations reported to date include: central nervous system manifestations (dizziness, headache, stroke, epileptic seizures, and impaired consciousness secondary to acute encephalopathy, encephalitis, and necrotising haemorrhagic encephalopathy); peripheral nervous system manifestations (impairment of taste, smell, and vision, and peripheral neuropathy); and skeletal muscular injury manifestations including rhabdomyolysis and myalgia $[4,6]$. The neurological manifestations of COVID-19 according to one study depends on the severity of the overall disease burden, and there are reports of the virus having neurotropism. We are therefore uncertain as to whether the novel coronavirus causes WMD. This is likely to be an area that warrants study.

\section{Step 2: Careful review of the neuroimaging patterns of WMD}

Careful review of the neuroimaging patterns of WMD is important. MRI of the brain is fundamental in the diagnostic workup of WMDs and reliably classifies WMD by identifying distinct structural pattern involvement specific to a disease entity [30, 31]. An MRI algorithm has been discussed [32] and subdivides MRI characteristics according to 1) prominent T2-hyperintensity and T1-hypointensity WMD, further subdivided into confluent and multifocal patterns, and 2) hypomyelination with mild $\mathrm{T} 1$ hyperintensity and $\mathrm{T} 2$ hyperintensity, T1 isointensity, or mild T1 hypointensity, further subdivided into peripheral or no peripheral nervous system involvement.

MRI discriminators have also been defined [32] and help to differentiate confluent and isolated patterns from multifocal ones. While inherited WMDs often present with bilateral, symmetric, and confluent MRI patterns, acquired cases demonstrate a multifocal, isolated, and asymmetric pattern; however, these disease-specific patterns may sometimes overlap (e.g. the bilateral, symmetric, and confluent pattern of human immunodeficiency virus / acquired immunodeficiency syndrome [HIV/AIDS] encephalopathy). In patients older than 18-months, other MRI discriminators help differentiate T2-hyperintensities due to delayed myelination or permanent hypomyelination from other forms of WMD and help localise confluent patterns to the frontal, parieto-occipital, periventricular, subcortical, or posterior fossa regions. Furthermore, while an MRI algorithm may be helpful in the diagnosis of WMD, the MRI brain findings in Case 2 remained stable despite progressive symptoms, thus impeding our efforts to make an aetiological diagnosis.
The pattern of WMD, combined with the clinical history, will help guide the approach to a more advanced laboratory or genetic testing. Abrupt, stroke-like, or multiple sclerosis-like attacks are completely different from a slowly progressive WMD. Nonspecific WMD patterns associated with uncontrolled hypertension and renal failure, which are amenable to education and risk factor management, should be identified and differentiated from specific, adult-onset, acquired WMDs. These include acute toxic WMDs from methamphetamine use and the inhalation of heroin vapour (e.g. chasing the dragon leukoencephalopathy), HIV/AIDS, progressive multifocal leukoencephalopathy from John Cunningham (JC) virus, and remote multiple sclerosis.

Since the COVID-19 pandemic onset, there has been a rapid increase in the number of studies reporting the neuroimaging findings of SARS-CoV-2 given the reports of neural tissue tropism. In patients with COVID-19, non-contrast CT head imaging has demonstrated symmetric hypoattenuation within the bilateral medial thalami with negative CT angiogram and venogram, while on T2 FLAIR MRI of the brain, hyperintensities have been reported within the bilateral medial temporal lobes and thalami with evidence of diffuse microhaemorrhages on SWI [33]. Based on these preliminary reports, a 'diencephalic encephalitis' pattern seems to suggest a severe viral attack on these deep brain structures.

As described above, neuroimaging in COVID-19 patients have shown a prevalence of $35 \%$ of non-specific white matter changes, and clinicians should be aware that demyelinating WMD variant could be underreported. Other reported findings on MRI of the brain in COVID-19 patients include cortical signal abnormalities on FLAIR, cortical diffusion restriction, leptomeningeal enhancement, and cortical blooming artifact [34].

\section{Step 3: Ancillary laboratory testing, genetic testing, and pathology}

As illustrated in the cases above, some patients with WMD can be diagnosed simply by means of Steps 1 and 2 (detailed history, neurological examination, and review of neuroimaging). However, as in Case 1, selected genetic testing for NOTCH3 gene mutation can yield a definitive diagnosis of CADASIL. While single-gene tests or whole genome sequencing can be considered, we generally recommend performing these in conjunction with a medical geneticist; if a genetic disorder is discovered, genetic counselling is often needed for the patient and offspring. Furthermore, optical coherence tomography (OCT) and OCT-angiography can be useful in measuring vessel density and thickness in the early detection of CADASIL white matter changes $[35,36]$.

Progressive multifocal leukoencephalopathy due to JC virus is an important differential diagnosis in immunocompromised adults. JC virus PCR in CSF is typically high enough to form the majority of diagnoses, albeit negative in rare cases [37]. On the other hand, while isolated case reports have 
indeed detected SARS-CoV-2 RNA in the CSF [38], other studies have been unable to isolate the virus and have only found an elevated total protein count, despite having a positive nasal swab and in the presence of neurological symptoms and/ or positive neuroimaging $[5,34,39]$.

Brain biopsy has been proposed in some cryptogenic WMD cases, but only yields a diagnosis $29-65 \%$ of the time, although this figure can be as high as $78 \%$ when a more discrete or localised lesion is identified on neuroimaging [40]. Brain biopsy in patients with WMD may be useful when the clinical state is deteriorating, when all tests have failed to provide a diagnosis, or when a treatable condition is suspected.

For progressive, neurodegenerative cases of WMD of unknown cause, autopsy remains the standard criterion for postmortem diagnosis [41-44]. It can better inform the offspring and guide family planning, contribute to our scientific understanding of WMD, and lead to better treatments. In Case 2, after multiple discussions with our patient about a brain biopsy, the patient refused to proceed given the uncertainty that a biopsy would yield a treatable diagnosis. The patient and her family understood that a final diagnosis after death via autopsy could be definitive, and they agreed to that approach.

We propose that undiagnosed patients with WMD be entered into multicentre National Organisation for Rare Diseases registries to help researchers across the globe make new discoveries that will hopefully translate into future cures.

\section{Conclusion}

While paediatric WMDs historically have a well-defined and literature-based clinical-laboratory approach to diagnosis, adult-onset WMD remains an important yet pathologically diverse radiographic phenotype, with different and distinct neuropathologies among the various subtypes of WMD.

We propose a three-step clinical approach to adult-onset WMD: 1) detailed history collection, including family and ethnic history, and neurological examination; 2) careful review of neuroimaging patterns; and 3) selective consideration of laboratory, genetic, and pathological means of diagnosis.

The combined clinical-imaging-laboratory approach to adult-onset WMD must continue to evolve if we are to shed more light on these conditions, and discover better therapies for cerebral WMDs.

Conflicts of interest: The authors have no conflict of interest to report.

Funding: This publication was prepared without any external source of funding.

Data availability statement: Data that supports the findings of this study is available from the corresponding author upon request. Author contributions: Dr Hasan contributed to conceptualisation, formal analysis, project administration, resources, supervision, visualisation, writing, and critical revision.
Dr Tipton contributed to formal analysis, resources, visualisation, and critical revision. Dr Vatz contributed to formal analysis, project administration, resources, supervision, visualisation, and critical revision. Ms Brown contributed to critical revision. Dr Thottempudi contributed to critical revision. Dr Kamireddi contributed to critical revision. Dr Atwal contributed to critical revision. Dr Wszolek contributed to critical revision. Dr Freeman contributed to conceptualsation, formal analysis, project administration, resources, supervision, visualisation, and critical revision. (C)2020 Mayo Foundation for Medical Education and Research.

\section{References}

1. Ahmed RM, Murphy E, Davagnanam I, et al. A practical approach to diagnosing adult onset leukodystrophies. J Neurol Neurosurg Psychiatry. 2014; 85(7): 770-781, doi: 10.1136/jnnp-2013-305888, indexed in Pubmed: 24357685.

2. Costello DJ, Eichler AF, Eichler FS. Leukodystrophies: classification, diagnosis, and treatment. Neurologist. 2009; 15(6): 319-328, doi: 10.1097/NRL.0b013e3181b287c8, indexed in Pubmed: 19901710.

3. Xiong YY, Mok V, Wong A, et al. Age-related white matter changes. J Aging Res. 2011; 2011(1): 617927-57, doi: 10.4061/2011/617927, indexed in Pubmed: 21876810.

4. Mao L, Jin H, Wang M, et al. Neurologic Manifestations of Hospitalized Patients With Coronavirus Disease 2019 in Wuhan, China. JAMA Neurol. 2020 [Epub ahead of print], doi: 10.1001/jamaneurol.2020.1127, indexed in Pubmed: 32275288.

5. Al Saiegh F, Ghosh R, Leibold A, et al. Status of SARS-CoV-2 in cerebrospinal fluid of patients with COVID-19 and stroke. J Neurol Neurosurg Psychiatry. 2020; 91(8): 846-848, doi: 10.1136/jnnp-2020-323522, indexed in Pubmed: 32354770.

6. Carod-Artal FJ. Neurological complications of coronavirus and COVID-19. Rev Neurol. 2020; 70(9): 311-322, doi: 10.33588/ rn.7009.2020179, indexed in Pubmed: 32329044.

7. Köhler W, Curiel J, Vanderver A. Adulthood leukodystrophies. Nat Rev Neurol. 2018; 14(2): 94-105, doi: 10.1038/nrneurol.2017.175, indexed in Pubmed: 29302065.

8. Lynch DS, Wade C, Paiva AR, et al. Practical approach to the diagnosis of adult-onset leukodystrophies: an updated guide in the genomic era. J Neurol Neurosurg Psychiatry. 2019; 90(5): 543-554, doi: 10.1136/ jnnp-2018-319481, indexed in Pubmed: 30467211.

9. O'Sullivan M, Jarosz JM, Martin RJ, et al. MRI hyperintensities of the temporal lobe and external capsule in patients with CADASIL. Neurology. 2001; 56(5): 628-634, doi: 10.1212/wnl.56.5.628, indexed in Pubmed: 11245715.

10. Hack R, Rutten J, Lesnik O, et al. In: Adam MP, Ardinger HH, Pagon RA, Wallace SE, Bean LH, Stephens K, et al., editors. GeneReviews [Internet]. Seattle, WA: University of Washington. Seattle, WA: University of Washington, Seattle. ; 2000.

11. Toma AK, Holl E, Kitchen ND, et al. Evans' index revisited: the need for an alternative in normal pressure hydrocephalus. Neurosurgery. 2011; 68(4): 939-944, doi: 10.1227/NEU.0b013e318208f5e0, indexed in Pubmed: 21221031.

12. Bartlett E, Mikulis DJ. Chasing "chasing the dragon" with MRI: leukoencephalopathy in drug abuse. Br J Radiol. 2005; 78(935): $997-$ 1004, doi: 10.1259/bjr/61535842, indexed in Pubmed: 16249600.

13. Singh R, Saini M. Toxic leucoencephalopathy after "chasing the dragon'. Singapore Med J. 2015; 56(6): e102-e104, doi: 10.11622/ smedj.2015094, indexed in Pubmed: 26106246. 
14. Filley CM, Kleinschmidt-DeMasters BK. Toxic leukoencephalopathy. N Engl J Med. 2001; 345(6): 425-432, doi: 10.1056/ NEJM200108093450606, indexed in Pubmed: 11496854.

15. Alambyan V, Pace J, Miller B, et al. The Emerging Role of Inhaled Heroin in the Opioid Epidemic: A Review. JAMA Neurol. 2018; 75(11): 1423-1434, doi: 10.1001/jamaneurol.2018.1693, indexed in Pubmed: 29987325.

16. Konno T, Yoshida K, Mizuno T, et al. Clinical and genetic characterization of adult-onset leukoencephalopathy with axonal spheroids and pigmented glia associated with CSF1R mutation. Eur J Neurol. 2017; 24(1): 37-45, doi: 10.1111/ene.13125, indexed in Pubmed: 27680516.

17. Eichler FS, Li J, Guo Y, et al. CSF1R mosaicism in a family with hereditary diffuse leukoencephalopathy with spheroids. Brain. 2016; 139: 1666-72.

18. Mochel F, Delorme C, Czernecki V, et al. Haematopoietic stem cell transplantation in CSF1R-related adult-onset leukoencephalopathy with axonal spheroids and pigmented glia. J Neurol Neurosurg Psychiatry. 2019; 90(12): 1375-1376, doi: 10.1136/jnnp-2019-320701, indexed in Pubmed: 31213485.

19. Zanin L, Saraceno G, Panciani PP, et al. SARS-CoV-2 can induce brain and spine demyelinating lesions. Acta Neurochir (Wien). 2020; 162(7): 1491-1494, doi: 10.1007/s00701-020-04374-x, indexed in Pubmed: 32367205.

20. Mahammedi A, Saba L, Vagal A, et al. Imaging in Neurological Disease of Hospitalized COVID-19 Patients: An Italian Multicenter Retrospective Observational Study. Radiology. 2020 [Epub ahead of print]: 201933, doi: 10.1148/radiol.2020201933, indexed in Pubmed: 32437313.

21. Renaud DL. Adult-Onset Leukoencephalopathies. Continuum (Minneap Minn). 2016; 22(2 Dementia): 559-578, doi: 10.1212/ CON.0000000000000303, indexed in Pubmed: 27042908.

22. Tavazzi E, White MK, Khalili K. Progressive multifocal leukoencephalopathy: clinical and molecular aspects. Rev Med Virol. 2012; 22(1): 18-32, doi: 10.1002/rmv.710, indexed in Pubmed: 21936015.

23. McKinney AM, Kieffer SA, Paylor RT, et al. Acute toxic leukoencephalopathy: potential for reversibility clinically and on MRI with diffusion-weighted and FLAIR imaging. AJR Am J Roentgenol. 2009; 193(1): 192-206, doi: 10.2214/AJR.08.1176, indexed in Pubmed: 19542414.

24. Lee SY, Dinesh SK, Thomas J. Hypertension-induced reversible posterior leukoencephalopathy syndrome causing obstructive hydrocephalus. J Clin Neurosci. 2008; 15(4): 457-459, doi: 10.1016/j. jocn.2006.12.019, indexed in Pubmed: 18249121.

25. Garrett LT, Hickman N, Jacobson A, et al. Family Studies for Classification of Variants of Uncertain Classification: Current Laboratory Clinical Practice and a New Web-Based Educational Tool. J Genet Couns. 2016; 25(6): 1146-1156, doi: 10.1007/s10897-016-9993-2, indexed in Pubmed: 27422780.

26. Cloak CC, Ernst T, Fujii L, et al. Lower diffusion in white matter of children with prenatal methamphetamine exposure. Neurology. 2009; 72(24): 2068-2075, doi: 10.1212/01.wnl.0000346516.49126.20, indexed in Pubmed: 19369643.

27. Donald KA, Roos A, Fouche JP, et al. A study of the effects of prenatal alcohol exposure on white matter microstructural integrity at birth. Acta Neuropsychiatr. 2015; 27(4): 197-205, doi: 10.1017/ neu.2015.35, indexed in Pubmed: 26022619.

28. Fryer SL, Schweinsburg BC, Bjorkquist OA, et al. Characterization of white matter microstructure in fetal alcohol spectrum disorders. Alcohol Clin Exp Res. 2009; 33(3): 514-521, doi: 10.1111/j.1530-0277.2008.00864.x, indexed in Pubmed: 19120066.

29. Lebel C, Warner T, Colby J, et al. White matter microstructure abnormalities and executive function in adolescents with prenatal cocaine exposure. Psychiatry Res. 2013; 213(2): 161-168, doi: 10.1016/j. pscychresns.2013.04.002, indexed in Pubmed: 23769420.

30. van der Knaap MS, Breiter SN, Naidu S, et al. Defining and categorizing leukoencephalopathies of unknown origin: MR imaging approach. Radiology. 1999; 213(1): 121-133, doi: 10.1148/ radiology.213.1.r99se01121, indexed in Pubmed: 10540652.

31. van der Knaap MS, Valk J, de Neeling $\mathrm{N}$, et al. Pattern recognition in magnetic resonance imaging of white matter disorders in children and young adults. Neuroradiology. 1991; 33(6): 478-493, doi: 10.1007/ BF00588038, indexed in Pubmed: 1780048.

32. Schiffmann R, van der Knaap MS. Invited article: an MRI-based approach to the diagnosis of white matter disorders. Neurology. 2009; 72(8): 750-759, doi: 10.1212/01.wnl.0000343049.00540.c8, indexed in Pubmed: 19237705.

33. Poyiadji N, Shahin G, Noujaim D, et al. COVID-19-associated Acute Hemorrhagic Necrotizing Encephalopathy: CT and MRI Features. Radiology. ; 2020: 201187.

34. Kandemirli SG, Dogan L, Sarikaya ZT, et al. Brain MRI Findings in Patients in the Intensive Care Unit with COVID-19 Infection. Radiology. 2020 [Epub ahead of print]: 201697, doi: 10.1148/radiol.2020201697, indexed in Pubmed: 32384020.

35. Fang XJ, Yu M, Wu Y, et al. Study of Enhanced Depth Imaging Optical Coherence Tomography in Cerebral Autosomal Dominant Arteriopathy with Subcortical Infarcts and Leukoencephalopathy. Chin Med J (Engl). 2017; 130(9): 1042-1048, doi: 10.4103/0366-6999.204935, indexed in Pubmed: 28469098.

36. Nelis P, Kleffner I, Burg MC, et al. OCT-Angiography reveals reduced vessel density in the deep retinal plexus of CADASIL patients. Sci Rep. 2018; 8(1): 8148, doi: 10.1038/s41598-018-26475-5, indexed in Pubmed: 29802397.

37. Rahmlow M, Shuster EA, Dominik J, et al. Leflunomide-associated progressive multifocal leukoencephalopathy. Arch Neurol. 2008; 65(11): 1538-1539, doi: 10.1001/archneur.65.11.1538, indexed in Pubmed: 19001176.

38. Moriguchi T, Harii N, Goto J, et al. A first case of meningitis/encephalitis associated with SARS-Coronavirus-2. Int J Infect Dis. 2020; 94: 55 58, doi: 10.1016/j.jiji.2020.03.062, indexed in Pubmed: 32251791.

39. Espinosa PS, Rizvi Z, Sharma P, et al. Neurological Complications of Coronavirus Disease (COVID-19): Encephalopathy. Cureus. 2020; 12(3): e7352, doi: 10.7759/cureus.7352, indexed in Pubmed: 32328364.

40. Gilkes CE, Love S, Hardie RJ, et al. Brain biopsy in benign neurological disease. J Neurol. 2012; 259(5): 995-1000, doi: 10.1007/s00415012-6455-0, indexed in Pubmed: 22361977.

41. Koga S, Roemer SF, Kasanuki K, et al. Cerebrovascular pathology presenting as corticobasal syndrome: An autopsy case series of "vascular CBS". Parkinsonism Relat Disord. 2019; 68: 79-84, doi: 10.1016/j. parkreldis.2019.09.001, indexed in Pubmed: 31621626.

42. Moghekar A, Kraut M, Elkins W, et al. Cerebral white matter disease is associated with Alzheimer pathology in a prospective cohort. Alzheimers Dement. 2012; 8(5 Suppl): S71-S77, doi: 10.1016/j. jalz.2012.04.006, indexed in Pubmed: 23021624.

43. Rost NS, Sadaghiani S, Biffi A, et al. Setting a gold standard for quantification of leukoaraiosis burden in patients with ischemic stroke: the Atherosclerosis Risk in Communities Study. J Neurosci Methods. 2014; 221: 196-201, doi: 10.1016/j.jneumeth.2013.10.009, indexed in Pubmed: 24459720.

44. Gouw AA, Seewann A, Vrenken H, et al. Heterogeneity of white matter hyperintensities in Alzheimer's disease: post-mortem quantitative MRI and neuropathology. Brain. 2008; 131(Pt 12): 3286-3298, doi: 10.1093/brain/awn265, indexed in Pubmed: 18927145. 